\section{Abuso de drogas e transtornos alimentares entre mulheres: sintomas de um mal-estar de gênero?}

\author{
Drug abuse and eating disorders in women: \\ symptoms of gender discomfort?
}

\author{
Abuso de drogas y trastornos de la alimentación \\ entre las mujeres: ¿síntomas de un malestar \\ de género?
}

Regina Helena Simões-Barbosa 1 Sônia Maria Dantas-Berger 2

doi: $10.1590 / 0102-311 \times 00120816$

\section{Resumo}

$O$ artigo discute o abuso de drogas e os transtornos alimentares sob as perspectivas críticas de gênero e do cuidado em saúde. Postula-se que o sofrimento subjetivo pode se expressar no corpo por meio das doenças psicossomáticas. Nessa perspectiva, a insaciável fome consumista das drogas ou de bens supérfluos, bem como o adoecimento pela fome voluntária em busca de um ideal de esbeltez, como na anorexia e bulimia, podem ser sintomas que denunciam o sofrimento feminino. Uma revisão nos campos da saúde coletiva e das teorias feministas destaca a magnitude dos fenômenos da medicalização e mercantilização da saúde presentes na psiquiatrização do mal-estar feminino. $\mathrm{Na}$ transição de gênero das sociedades capitalistas, as cobranças sociais pelo desempenho dos velhos e novos papéis femininos acentuam sentimentos de inadequação, traduzidos no mal-estar de gênero que circunda o abuso de drogas e os transtornos alimentares, analisados como patologias de protesto. Propõe-se o resgate do ideário do Programa de Assistência Integral à Saúde da Mulher orientado pela integralidade, para enfrentar tais desafios.

Gênero e Saúde; Transtornos Relacionados ao Uso de Substâncias;

Transtornos da Alimentação e da Ingestão de Alimentos;

Integralidade em Saúde

\section{Correspondência}

R. H. Simões-Barbosa

Instituto de Estudos em Saúde Coletiva, Universidade Federal do Rio de Janeiro.

Praça Jorge Machado Moreira 100, Rio de Janeiro, RJ 21941-580, Brasil.

reginacasa@gmail.com

1 Instituto de Estudos em Saúde Coletiva, Universidade Federal do Rio de Janeiro, Rio de Janeiro, Brasil.

2 Instituto de Saúde Coletiva, Universidade Federal Fluminense, Niterói, Brasil. 


\section{Notas introdutórias}

Propomos, neste ensaio, uma reflexão sobre o abuso de drogas e transtornos alimentares entre mulheres em uma perspectiva crítica de gênero que aborda estes agravos como sintomas das contradições que perpassam as relações sociais de gênero nas sociedades capitalistas contemporâneas.

Partimos do pressuposto de que esses problemas, que afetam o corpo e a alma, podem estar manifestando sintomas de uma sociedade problemática. Na ausência de uma voz política coletiva, o sofrimento subjetivo pode se expressar por meio da linguagem corporal, como nas doenças psicossomáticas, que podem ser lidas como uma forma de protesto: individual, autorreferido e autodestrutivo, mas ainda protesto 1,2. Assim, a insaciável fome consumista, seja das drogas ou de bens supérfluos, ou a morte pela fome voluntária, como na anorexia e bulimia, serão aqui analisadas como sintomas que podem estar denunciando, simbólica e concretamente, a fome humana por afeto, confiança e solidariedade em um mundo crescentemente desigual, competitivo, individualista e violento 3 .

Algumas indagações nos instigaram a refletir sobre esses temas: o que vem induzindo cada vez mais mulheres a abusarem de drogas, especialmente as lícitas, prescritas para atenuar sentimentos de ansiedade, angústia e depressão? Por que tantas jovens, que deveriam estar empregando suas energias na construção de projetos de vida, jejuam até a morte por inanição, em busca de um ideal de esbeltez irreal e inatingível? No campo dos excessos, o que leva cada vez mais mulheres a se tornarem adictas de bebidas alcoólicas e do tabaco? O que podem significar esses apetites excessivos?

As respostas, a nosso ver, não são simples nem objetivas e exigem o desvelamento e a compreensão de complexas dimensões da vida humana que estão aí estreitamente enredadas, dos poderosos interesses econômicos que alimentam, por meio de estratégias de marketing cada vez mais sofisticadas, um lucrativo mercado relacionado ao corpo e à estética, à esfera da subjetividade e das representações que produzem nas mulheres uma crônica insatisfação com o seu corpo e aparência, gerando processos autodestrutivos de várias ordens, tais como o abuso de drogas e os transtornos alimentares.

Essas questões recolocam o desafio de identificarmos e (re)interpretarmos as contradições de uma sociedade que objetifica e mercantiliza até as esferas mais íntimas das relações humanas, tornando todos/as reféns de suas ideologias. Para Bauman 4, as relações sociais contemporâneas carregam as marcas da instabilidade, fragilidade e incerteza, gerando um medo difuso que emana de todos os espaços, dos vínculos instáveis de trabalho à volatilidade das relações amorosas, das ameaças tóxicas - alimentares e ambientais, entre outras - ao risco que se corre nas ruas, sendo que todos estes medos se retroalimentam, gerando um ambiente de insegurança que nos faz sentir permanentemente ameaçados, experimentando uma ansiedade difusa que não nos permite discriminar a que, e como, reagir. Segundo ele, é essa característica líquida do medo que impulsiona sua exploração política e comercial nas sociedades capitalistas. Não estará o crescente consumo de psicofármacos, usualmente utilizados para aliviar o sofrimento, relacionado a esses processos?

Na sociedade de consumo, novas necessidades, desejos e exigências são constantemente produzidos, alimentando a ilusão da liberdade de escolha. Bauman 4 identifica anorexia e bulimia como reações somáticas às contradições geradas por um estilo de vida baseado no consumismo e na satisfação egocêntrica de necessidades - reais e ilusórias.

Para melhor compreender esse cenário de agravos à saúde que se manifestam no corpo e na alma, revisitamos teorias feministas que tomaram o corpo como âncora conceitual para analisar a condição das mulheres na sociedade, compreendendo os processos somáticos femininos como expressões das contradições de gênero que, a despeito das conquistas obtidas pelos movimentos de mulheres, continuam, sob o capitalismo, a se atualizar, nos sinalizando que, mais do que nunca, é necessário retomar as estratégias coletivas - políticas - para o enfrentamento das várias expressões da desigualdade social, como o feminismo inaugural do século XX tão bem compreendeu.

Inicialmente, analisamos o abuso de drogas e os transtornos alimentares no cenário da saúde das mulheres no Brasil, em que novos problemas se somam aos anteriores. Em seguida, apresentamos pesquisas que identificam aspectos relevantes para a compreensão dos agravos em foco. Segue uma discussão sobre a condição das mulheres no contexto das sociedades capitalistas contemporâneas, sinalizando para as conexões entre a sociedade de risco 5 e o mal-estar de gênero que circunda o abuso de drogas e os transtornos alimentares. Uma leitura feminista sobre o corpo é, então, empreendida, analisando-se particularmente os agravos que são objeto deste trabalho. Por fim, propomos algumas 
reflexões que julgamos pertinentes para as políticas públicas de enfrentamento desses problemas, em especial a Política Nacional de Atenção Integral à Saúde da Mulher (PNAISM) 6.

\section{O cenário de saúde das mulheres: o que há para comemorar?}

A despeito dos esforços empreendidos pelos movimentos de mulheres, profissionais de saúde e pesquisadoras/es em defesa do ideário do Programa de Assistência Integral à Saúde da Mulher (PAISM), o cenário de saúde das brasileiras permanece preocupante.

Uma das principais frentes de atuação do PNAISM está situada no campo da saúde reprodutiva. Apesar de alguns avanços recentes, persistem graves problemas, tais como a larga extensão da prática da laqueadura tubária, associada ao parto cesáreo iatrogênico; o acesso precário e insuficiente a métodos contraceptivos comuns; as alarmantes estimativas de morbi-mortalidade feminina decorrentes de abortos inseguros; a alta incidência de doenças sexualmente transmissíveis (DST) entre as mulheres, especialmente o HIV/AIDS; a inaceitável persistência de altas taxas de mortalidade materna, entre outras. Há que se mencionar as graves interações entre a saúde sexual e reprodutiva e a violência doméstica contra as mulheres, que provocam, além das dolorosas consequências psíquicas, gravidez indesejada, infecção pelo HIV e outras DSTs e, frequentemente, abortos realizados em condições inseguras.

A recente epidemia de Zika vírus vem trazer novos e alarmantes desafios para a saúde das mulheres. Segundo Diniz 7 , a epidemia coloca em evidência a fragilidade da garantia dos direitos sexuais e reprodutivos no país. Um recente Ministro da Saúde, ao assumir, sugeriu que as mulheres não engravidassem, um desrespeito à autonomia reprodutiva e uma recomendação que a maioria das brasileiras sequer poderia cumprir, já que não há políticas adequadas de planejamento familiar, direito ao aborto legal, acesso regular a contraceptivos e a políticas sociais que garantam apoio às famílias, principalmente às mães que, geralmente sozinhas, assumem os intensivos e complexos cuidados de seus filhos microcefálicos. Quantas dessas mulheres já fazem parte das altíssimas taxas de morbi-mortalidade decorrentes de abortamento inseguro?

No campo dos agravos não reprodutivos, permanecem altas as taxas de incidência dos cânceres femininos e da morbi-mortalidade decorrentes das doenças do aparelho cardiocirculatório, confirmando o que Giffin denominou "modernidade perversa", em que problemas decorrentes da pobreza e falta de acesso a serviços coexistem com agravos relacionados aos novos estilos de vida, além da iatrogenia provocada pelo excesso de intervenção médica 8,9.

O abuso de drogas e os transtornos alimentares vêm se agregar a esse preocupante cenário, complexificando-o. Uma breve revisão de estudos sobre a temática permite contextualizar o tema no campo da Saúde Coletiva.

\section{Abuso de drogas e transtornos alimentares: qual a magnitude destes problemas para a saúde das mulheres?}

Optamos por enfatizar a questão das drogas lícitas por explicitarem a intensidade e magnitude dos fenômenos da medicalização do corpo feminino 10 e da mercantilização da saúde 11,12. Além disto, os psicofármacos são drogas que, por atuarem na sustentabilidade de um cotidiano problemático, reforçam os mecanismos de acomodação; e, por serem drogas legais e prescritas, o problema do abuso e da dependência está obscurecido e banalizado, reforçando a importância de expô-lo.

Alguns estudos evidenciam que vem aumentando em todo o mundo o consumo de psicofármacos entre as mulheres 13 , assim como o número de mulheres tabagistas e alcoolistas 14,15, configurando-se uma feminização desses problemas.

O II Levantamento Domiciliar Sobre o Uso de Drogas Psicotrópicas no Brasil 13 (p. 390) revelou "que as mulheres usam mais Benzodiazepínicos que os homens na proporção de 2:1, e os Anfetamínicos, na proporção de 4:1".

Um estudo realizado na rede básica de saúde brasileira confirmou a larga utilização dos benzodiazepínicos por mulheres, especialmente as mais velhas (entre 50 e 69 anos), em relacionamento estável 
e analfabetas; o uso crônico (por mais de 6 meses) alcançou 89\% delas e a tentativa infrutífera de interrupção foi de $69 \%$ 16. Carvalho \& Dimenstein 17 destacam que esse amplo processo de medicalização envolve desde aspectos econômicos, reforçados pela lógica capitalista, até o paradigma biomédico hegemônico, norteado pela lógica biologicista.

Miguelote \& Camargo Jr. 18 evidenciaram o processo de ativa colaboração entre a indústria farmacêutica e a "indústria do conhecimento" que, associadas, induzem a cultura da prescrição indiscriminada das drogas para a resolução de todos os males. Como é sabido, o consumo sem controle dessas drogas pode levar - e frequentemente leva - à dependência física e psíquica, com graves consequências pessoais, familiares e sociais 17 .

A medicalização do mal-estar resultante de diversos tipos de discriminação e violência, baseadas ou não no gênero, que muitas mulheres vivenciam ou testemunham - violência estrutural, institucional, étnico-racial, urbana, doméstica, sexual, no trabalho - vem se tornando um recurso legitimado, gerando o que se pode considerar uma "violência farmacológica" 19. Desse modo, o "calmante", em suas doses de sono e tranquilidade artificiais, atua como verdadeira "mordaça química", aprisionando resistências e reproduzindo desigualdades 17 .

As drogas, lícitas e ilícitas, também são usadas por seus efeitos de prazer, para melhorar a performance social, enfrentar situações difíceis e, especialmente, como automedicação para conter a ansiedade gerada por um mal-estar difuso e inominável. Estudos recentes sobre tabagismo feminino evidenciaram que o cigarro é significado pelas mulheres como um "companheiro", que atenua as tensões geradas pelas exigências cada vez maiores, mas também proporcionando (raros) momentos de prazer e relaxamento 14,20 .

Com relação ao consumo de álcool no Brasil, a prevalência estimada da dependência de álcool chega a 17,1\% entre homens e 5,7\% entre mulheres, ou seja, 3 homens alcoolistas para cada mulher 21. $\mathrm{O}$ abuso de substâncias psicoativas foi considerado por longo tempo um problema eminentemente masculino; porém, constata-se um grande desconhecimento sobre as dependências femininas em decorrência de preconceitos e estigmas baseados em estereótipos de gênero 15,22,23.

Buscando compreender o alcoolismo feminino em perspectiva de gênero, César 15 identificou, entre as alcoolistas investigadas, sentimentos de inadequação, tanto às expectativas tradicionais da feminilidade quanto às exigências sobre esta nova "mulher Atlas" 24, que carrega o mundo nas costas e deve ser bem-sucedida em todas as esferas da vida, pública e privada. Conclui que "o processo de lidar com experiências adversas e fugir do sofrimento, resistindo à violência e ao desamparo numa tentativa de ficar alegre e mais sociável, revela-se, ao mesmo tempo, num beber solitário, depressivo, auto destrutivo” 15 (p. iv). A autora também identificou uma preocupante associação do beber feminino com a violência, revelando os entrecruzamentos entre variadas ordens de opressões que se potencializam mutuamente.

Alguns aspectos aqui apresentados sugerem que as mulheres dependentes de substâncias psicoativas podem demandar uma abordagem diferenciada nos serviços de saúde. Entre outros obstáculos que precisam ser considerados, destacam-se a vergonha frente aos estigmas imputados às mulheres "viciadas" e, caso decidam se tratar, a falta de apoio social para o desempenho de suas funções domésticas e profissionais 23 .

No que diz respeito aos transtornos alimentares, estudos confirmam que as mulheres continuam sendo o grupo mais afetado 25 , embora os homens também estejam sendo atingidos. Observa-se, entre elas, o aumento da incidência da obesidade, assim como de anorexia e bulimia, que afetam principalmente as jovens.

As mulheres com transtornos alimentares apresentam preocupação desmedida com o peso, distorção da imagem corporal e desejo compulsivo de emagrecer, independentemente do peso. Um estudo qualitativo realizado em Fortaleza (Ceará) com portadoras de anorexia, bulimia e transtorno do comer compulsivo concluiu que "o medo de engordar é apontado como sendo algo coletivo, que povoa o imaginário feminino" 26 (p. 702).

No que diz respeito às motivações estéticas, Bosi \& Andrade 25 chamam atenção para as síndromes parciais de comportamentos precursores dos transtornos alimentares, tais como "vômitos auto-induzidos, uso de laxantes, jejuns prolongados, diuréticos e anorexígenos associados, muitas vezes, à prática excessiva de exercícios físicos” 25 (p. 198), tão frequentes entre mulheres, principalmente as adolescentes e adultas jovens. 
Um estudo realizado em farmácias de manipulação em Natal (Rio Grande do Norte) verificou que em 22.158 notificações contendo substâncias anoréticas, do tipo anfetamina (prescritas nas "fórmulas mágicas" de emagrecimento), ou benzodiazepínicos, eram as mulheres as maiores consumidoras. Falhas e erros no preenchimento das prescrições revelaram fraudes, descaso e banalização de seus efeitos na saúde das mulheres 27 . Com relação ao uso/abuso de anfetaminas, pesquisas têm evidenciado a larga extensão do uso desta perigosa droga entre as mulheres jovens 28,29 .

Como pontuam Bosi \& Andrade 25, anorexia e bulimia, por um lado, e obesidade, por outro, refletem interesses mercantis em disputa, configurando os conflitos entre um agressivo incentivo ao "consumo" alimentar via indústrias de fast food e a exigência de magreza e sujeição a um ideal estético cada vez mais difícil de atingir.

Esse cenário conduz a uma inquietante (auto)reflexão: após tantas lutas e conquistas alcançadas pelas mulheres e que resultaram, ao menos parcialmente, no reconhecimento e institucionalização de direitos de cidadania feminina, o que os fenômenos do abuso de drogas e dos transtornos alimentares estão nos sinalizando? Estarão expressando um mal-estar de gênero?

\section{A transição de gênero nas sociedades capitalistas contemporâneas: quem é a nova mulher?}

Para situar os processos sociais em curso que afetam a vida e a saúde das mulheres, abordaremos aqui as determinações que perpassam a feminilidade em suas dimensões objetivas e subjetivas, materiais e simbólicas.

Giffin 30 caracterizou como transição de gênero o processo histórico em que, com o rebaixamento do valor do salário do provedor masculino e, mais recentemente, o aumento do desemprego, da instabilidade e da precariedade dos vínculos de trabalho, as mulheres gradativamente vêm sendo responsabilizadas, e se sentem responsáveis pela provisão de renda, mesmo (ou principalmente) tendo filhos menores 29,30,31.

Essa transição de gênero, porém, tem sido ideologicamente representada como uma nova mulher que conquista independência mediante o seu trabalho remunerado, o que encobre a intensificação da exploração do trabalho feminino e o aprofundamento da dupla jornada de trabalho, contribuindo para a reprodução das desigualdades sociais e de gênero 29,30,31.

Em um cenário de feminização da pobreza, que se dissemina em todas as sociedades capitalistas (Anderson, 1994, apud Brito 32), grande parte dos problemas de saúde que afetam a maioria das mulheres está relacionada à sobreposição do trabalho remunerado às responsabilidades com a vida doméstica, agravada pela ausência do Estado e de políticas públicas que poderiam minimizar estas dificuldades ${ }^{32}$. Se considerarmos que as opressões raciais e étnicas se entrelaçam às de gênero e classe, pode-se supor que um contingente considerável de mulheres negras, indígenas, quilombolas e outras são hoje, possivelmente, as parcelas mais exploradas da população.

Análises feministas sobre a globalização neoliberal vêm sinalizando que as mudanças econômicas em curso se sustentam no sistema de gênero, tensionando-o e provocando mudanças em seu interior. Segundo Vargas 33, em todos os processos de ajuste estrutural as mulheres têm sido um fator oculto de equilíbrio para absorver os choques dos programas de ajuste da economia, tanto intensificando o trabalho doméstico - para compensar a diminuição dos serviços sociais decorrente da redução do gasto público - como pelo fato de que a privatização dos sistemas de seguridade social incidiram, em maior medida, sobre as mulheres, que assumem individualmente e sem apoio estatal os custos sociais da maternidade. Assim, sua posição na família e no mercado de trabalho as coloca como parte da estratégia desreguladora do mercado. Ao não se considerar o valor do trabalho reprodutivo, as mulheres tendem a dobrar a sua carga de trabalho produtivo e reprodutivo (a "servidão voluntária", segundo Hirata 34$)$, o que se acentua em tempos neoliberais, quando as responsabilidades dos Estados frente ao bem-estar da cidadania são deslocadas para o setor privado 33 .

Ao analisar a participação das mulheres no mercado de trabalho, Bruschini 35 identifica a persistência da baixa qualidade do emprego feminino, com predomínio da informalidade e precariedade. Como mostram Díaz \& Medel (1997, apud Brito 32), o trabalho temporário e o vínculo precário geram temor e ansiedade, o que está relacionado às doenças mentais. $\mathrm{O}$ trabalho em domicílio, outra moda- 
lidade de emprego feminino em que as mulheres têm de administrar trabalho remunerado e tarefas domésticas, também é gerador de estresse e ansiedade entre as trabalhadoras.

Nesse cenário, não há como não relacionar o consumo abusivo de drogas, os transtornos alimentares e outras manifestações psicossomáticas à superexploração do trabalho feminino, assim como às cobranças sociais pelo (bom) desempenho dos papéis da mulher - a boa mãe, a dedicação aos outros, o cuidado de todos - que tanto acentuam os sentimentos de infelicidade, inadequação e frustração associados às desordens psíquicas.

Tomando-se o corpo como instância de reprodução das ideologias da feminilidade, mas também de resistência a elas, apresentamos, a seguir, uma leitura do corpo feminino como lócus de expressão de patologias de protesto, contextualizado nos processos de mercantilização dos corpos.

\section{O corpo mercantilizado}

Ao analisar o paradigma do pensamento filosófico ocidental que instituiu a dicotomia mente x corpo e elegeu a razão como qualidade inerente ao sujeito pensante, Chauí 36 argumenta que esta representação, que desvaloriza o corpo, permite (e justifica) a sua apropriação, no capitalismo, como mercadoria, não só como força de trabalho mas como objeto de consumo.

Segundo Freire-Costa ${ }^{37}$, no decorrer do processo de constituição do capitalismo, corpos e sentimentos foram sendo apropriados e transformados em novas mercadorias, tornando-se objeto de manipulação comercial e publicitária. Assim, gradativamente deixamos de perceber que “...o que está sendo verdadeiramente 'consumido' é a vitalidade de nossos corpos e mentes, diariamente vendida e comprada, usada e abusada para azeitar a máquina ensandecida do lucro" 37.

Uma importante estratégia de apropriação do corpo, e que diz respeito aos temas deste ensaio, é sua intensa medicalização, fomentada pelos interesses da poderosa indústria farmacêutica, que não mede recursos e meios para induzir o consumo de fármacos, tais como criar novas patologias ou mesmo exagerar na ameaça de algumas, de forma a ampliar o mercado consumidor 18.

Freire-Costa 37, ao analisar os impactos desses processos sobre as subjetividades e os corpos, e as respostas compensatórias (autodestrutivas) de várias ordens, denuncia que:

“Observadas de perto, as promessas da 'sociedade de consumo' são espantosas. Tudo cabe numa lista tacanha, onde, de um lado, estão os meios de evasão - a cocaína, o ecstasy ou o mais novo psicotrópico contra o mais novo sofrimento existencial - e, de outro, a realidade social da qual todos querem se evadir - o tédio; a aridez da inveja e da competição; o medo do desemprego; o tormento das decepções românticas; a obsessão pela magreza e pela boa-forma; a anorexia; a bulimia; as mutilações corporais; as pancadarias adolescentes dos fins de semana; a depressão; a insônia crônica; o estigma da obesidade; o receio da solidão; o exame fóbico das taxas de colesterol; enfim, o pavor do câncer, do infarto, da doença de Alzheimer, da 'feiúra', da velhice, etc.".

Não casualmente, a depressão vem se tornando a principal queixa nos consultórios, alimentando o insaciável mercado de psicofármacos, o que Kehl interpreta como “... a expressão do mal-estar que faz água e ameaça afundar a nau dos bem-adaptados ao século da velocidade, da euforia prêt-à-porter, da saúde, do exibicionismo e, como já se tornou chavão, do consumo generalizado" 38 (p. 22).

O corpo feminino, corpo reprodutivo, é emblemático desse processo pois nele são exercidos diretamente mecanismos de controle político. Não por acaso, foi alvo prioritário da intervenção médica ao longo dos últimos dois séculos 10,39. A seguir, abordaremos o corpo como um texto da feminilidade, instância prática de exercício de controle e poder sobre as mulheres 2.

\section{O corpo e a reprodução da ideologia de gênero}

"Felicidade é caber num vestido tamanho P!" (outdoor de uma grife feminina em Fortaleza).

Historicamente, a disciplinarização do corpo feminino tem sido uma estratégia surpreendentemente durável e flexível de controle social, sendo o sistema de saúde um importante aliado no exercício destas práticas de (bio)poder 2.

Nesta sociedade, que frequentemente exalta as conquistas femininas e aponta para um (suposto) poder da mulher, novas estratégias disciplinares vêm sendo acionadas em torno de um irreal e ina- 
tingível ideal de feminilidade, que exige das mulheres uma busca insana e incansável por mudanças supérfluas e extravagantes em seus corpos, impulsionadas por um ávido segmento empresarial da indústria alimentícia e de produtos estéticos em expansão. Assim, as mulheres despendem cada vez mais tempo com o tratamento e a disciplina de seus corpos, "habituando-os" - por meio de dietas, maquiagem, vestuário, plásticas, musculação - ao controle externo, à sujeição, à transformação e ao aperfeiçoamento. Segundo Bordo 2, é por intermédio dessas disciplinas que memorizamos nos corpos o sentimento de carência e insuficiência, sendo que, em casos extremos, as práticas de feminilidade podem levar à debilitação e à morte. Como alerta: "Uma batalha política está sendo travada sobre a energia e os recursos do corpo feminino, uma batalha na qual pelo menos algumas metas feministas, previstas para dar poder às mulheres, estão sendo derrotadas" 2 (p. 36).

Para Anyon 1, as mulheres, ao enfrentarem valores e atitudes impostos pela sociedade patriarcal, desenvolvem respostas ativas às contradições sociais na tentativa de solucionarem as mensagens antagônicas que recebem. Dessa perspectiva, a passividade feminina é um mito e as mulheres, mesmo que de formas não explícitas ou não verbais, resistem à opressão adotando estratégias de resistência para equacionar as mensagens sociais contraditórias sobre a feminilidade.

Nos (contraditórios) processos de socialização, as mulheres são educadas para serem emotivas, dedicarem-se ao cuidado dos outros e não serem competitivas. Porém, a ideologia capitalista, calcada no individualismo e na competição, exige comportamentos objetivos, racionais, agressivos e competitivos, que entram em franca contradição com a socialização de gênero (ainda) hegemônica. Para Anyon 1, a maioria das mulheres não aceita nem rejeita totalmente os imperativos da feminilidade e, geralmente, optam por resistir cotidianamente à opressão e à baixa autoestima, adotando estratégias de resistência e acomodação, sendo as doenças mentais um dos dolorosos e autodestrutivos processos de acomodação na resistência.

Assim, histeria e frigidez, anorexia e bulimia podem expressar somaticamente conflitos internos relacionados às contradições de gênero. Alcoolismo e dependência de drogas também podem ser vistos como formas escondidas de protesto, que expressam resistência à opressão de formas privadas, discretas e aquiescentes 1.

A sintomatologia, nessa perspectiva, aponta para o significado simbólico e político na construção histórica do gênero: o corpo, marcado pela expectativa da feminilidade de cada época, exprime aquilo que as condições sociais e políticas tornam impossível verbalizar. Nessas patologias, as mulheres usam a linguagem corporal da feminilidade para contestar os dilemas do seu mundo e de sua época histórica 2 .

Segundo Bordo, é "por meio de disciplinas rigorosas e reguladoras sobre a dieta, a maquiagem e o vestuário - princípios organizadores centrais do tempo e do espaço nos dias de muitas mulheres - [que] somos convertidas em pessoas menos orientadas para o social e mais centradas na auto-modificação", desmobilizando potenciais de rebeldia, contestação e de engajamento político 2 . E alerta que: "nos casos extremos, as práticas da feminilidade podem nos levar à absoluta desmoralização, à debilitação e à morte” 2 (p. 20).

Nessa perspectiva conceitual e política, o abuso de drogas e os transtornos alimentares podem ser reveladores do quanto as mulheres ainda se encontram presas às contradições que deveriam superar.

\section{As patologias de protesto femininas: histeria, agorafobia e anorexia/bulimia}

Bordo 2 identifica algumas patologias de protesto que, em determinados períodos históricos, expressam as contradições - ou um mal-estar - de gênero característico do contexto sociopolítico daquele momento.

Diante disso, a histeria pode ser vista como manifestação somática da rígida repressão sexual da era vitoriana, afirmando-se como patologia feminina no período da Revolução Francesa, quando o capitalismo se consolidou excluindo as mulheres das concepções de liberdade e direitos.

Na segunda metade do século XX, a agorafobia se instalou como patologia que afeta principalmente as mulheres. Essa fobia do mundo da rua expõe, segundo Bordo, uma nova contradição de gênero: a preservação dos ideais femininos da domesticidade em confronto com as exigências do mundo público do trabalho remunerado. A mulher agorafóbica, confinada em casa, com medo do espaço público, vive literalmente essa construção ambígua da feminilidade, não casualmente no momento em 
que as mulheres já estão massivamente participando do mercado de trabalho remunerado, quando um número significativo de mulheres começa a beber e fumar, sendo estes hábitos associados, pela mídia e pelas indústrias de tabaco e bebidas alcoólicas, à auto-afirmação feminina no mundo público ${ }^{14}$.

Nas últimas décadas do século XX, a patologia como forma de protesto foi atualizada por meio das desordens alimentares. De acordo com Bordo 2, o corpo anoréxico pode ser visto como uma caricatura do ideal contemporâneo de esbelteza exagerada para as mulheres. A ideologia da feminilidade continua apregoando concepções domésticas do ser mulher que incluem a divisão sexual do trabalho, o papel das mulheres como nutrizes da família e da comunidade, paralelamente à mulher profissional, que deve ser competente, competitiva, esbelta e musculosa, à semelhança dos homens.

Nessa ambiguidade conflituosa, qualquer apetite passa a ser considerado excessivo e a recusa à comida, concomitante ao afinamento do corpo, pode denunciar uma sociedade que despreza e suprime, simbólica e concretamente, a "fome" feminina por auto-afirmação e liberdade, exigindo um trabalho disciplinado para a modelação de corpos cada vez mais esquálidos. Dessa forma, o simbolismo corporal expressa as representações dominantes, como em um protesto às avessas: as mulheres devem desprezar as partes do corpo que as caracterizam como fêmeas e, à proporção que perdem as curvas, assemelhando-se a um corpo masculino, consideram-se poderosas e invulneráveis 2. Com perplexidade, perguntamos: que poder as mulheres almejam? Bordo 2 (p. 31-2) alerta: "Remodelar um corpo para torná-lo mais masculino não é ganhar poder e privilégios masculinos. Sentir-se autônoma e livre enquanto atrela corpo e alma a uma atividade obsessiva é servir a uma ordem social que limita as possibilidades femininas, e não transformá-la”.

O início das desordens alimentares surge das dietas, fomentadas por um agressivo mercado de alimentos dietéticos e tratamentos estéticos voltados para a modelação do corpo. Num país que cultua a beleza e a exposição do corpo, as dietas podem gerar estresse psicológico e ansiedade nas mulheres, potencializando a utilização de outros métodos de controle de peso, como, por exemplo, o cigarro e bebida alcoólica, além dos anorexígenos, drogas lícitas que provocam graves quadros de dependência. O grupo etário mais insatisfeito com a aparência é composto pelas adolescentes entre 12 e 19 anos. Não coincidentemente, é nesse grupo que o cigarro é mais usado como forma de controle de peso 20.

Podemos prever que o século XXI será a era das drogas, lícitas e ilícitas. Em uma sociedade crescentemente contraditória e violenta, as drogas proporcionam, além de alívio imediato do sofrimento, uma rota de escape para os infindáveis problemas e dificuldades que povoam o cotidiano da maioria das pessoas, tanto na vida privada quanto na pública.

Encerramos provisoriamente este debate com uma pergunta provocadora: quem são e como estão as novas mulheres, celebradas pela mídia, que tudo podem, conquistam e fazem? A despeito do avanço da participação feminina em postos de comando e liderança profissional e política, a maioria das mulheres ainda se encontra aprisionada nas contradições de uma sociedade que não está voltada para a promoção do bem-estar coletivo, em especial de sua parcela feminina.

\section{Considerações finais}

Ao socializarem as experiências corporais íntimas em grupos de reflexão, as primeiras feministas romperam o silêncio e o desconhecimento sobre o corpo e a sexualidade, fazendo emergir a problematização da condição das mulheres na sociedade e a consciência crítica que foi transmutada em movimento político que, então, bradou: "Nosso corpo nos pertence!".

Os temas tratados neste ensaio nos mostraram, porém, que o corpo feminino permanece colonizado por poderes mercantis e ideológicos, que só podem ser enfrentados mediante a transformação deste modelo de sociedade.

Algumas considerações finais devem ser feitas. Em primeiro lugar, é inadiável o enfrentamento do modelo biomédico mercantil, que medicaliza a vida, a subjetividade e o corpo, aprisionando todos, homens e mulheres, à dependência da "pílula mágica" como solução para males que são socialmente gerados. Dessa forma, despotencializam-se as energias, a capacidade de luta e de enfrentamento coletivo/político das reais causas do sofrimento, além de se manter um mercado consumidor de drogas lícitas que sustenta um ramo empresarial que não tem demonstrado qualquer compromisso com o bem-estar humano. 
No que diz respeito às mulheres, evidenciamos o quanto as ideologias de gênero que perpassam a assistência à saúde permanecem ativas, ocultando as reais necessidades de saúde das mulheres e impulsionando a medicalização do sofrimento feminino, alimentando a mercantilização da vida e da saúde.

Quanto aos problemas de saúde aqui analisados, destacamos a importância de se levar em consideração as políticas para as mulheres 40 e da atenção integral a usuários de álcool e outras drogas 41 . Além disso, enfatizamos a importância de se incorporar às pautas do PNAISM os transtornos alimentares, compreendidos como agravos relacionados às relações de gênero e que demandam, portanto, assistência pela ótica da integralidade. Um dos princípios que orienta o II Plano Nacional de Políticas para as Mulheres é o da autonomia, por meio do qual se busca priorizar a "defesa do poder de decisão sobre suas vidas e corpos", assim como "romper com o legado histórico, com os ciclos e espaços de dependência, exploração e subordinação que constrangem suas vidas no plano pessoal, econômico, político e social" 40 (p. 8). Resta saber até que ponto os processos de objetificação das mulheres, que são expressos pelas patologias do corpo e da alma, vêm sendo pautados e problematizados nas ações propostas e implantadas por meio de uma perspectiva de gênero transversal que não reduza os sentidos da conquista de autonomia e poder ao (ilusório) jargão "mais mulheres no poder".

Com relação à assistência à saúde das mulheres, mais uma vez levantamos a urgência de se retomar o ideário do PAISM e as lutas por sua efetiva implantação. Como há muito sabemos, somente um modelo assistencial orientado pela ótica da integralidade e que tenha como eixo condutor o reconhecimento dos direitos das mulheres, poderá abordar esses graves problemas de saúde impulsionando as mulheres, mesmo que circunscritas aos limites do possível, a buscarem transformações em suas vidas, ao invés de se aprisionarem nos esquemas medicamentosos que atuam como "mordaças químicas" na sustentação de um cotidiano de sofrimento e frustrações 17.

Nesse horizonte político está a luta por um modelo de Estado comprometido com a promoção do bem-estar social para todos e todas por meio de políticas públicas universais e com participação popular, o que, na atual conjuntura brasileira, pressupõe, entre outras questões, o enfrentamento das propostas privatizantes que, cada vez mais, rondam e tomam o lugar da gestão do setor público de saúde.

Por fim, julgamos fundamental resgatar o projeto de sociedade proposto pelo movimento de mulheres que trazia, nos "corações e mentes", uma proposta radical de transformação do mundo. Na utopia inaugural do feminismo, as mulheres reivindicavam, junto à igualdade econômica e social, um mundo regido pelos valores do cuidado, da solidariedade e do afeto, aprofundando e qualificando, assim, as (justas) reivindicações dos movimentos alinhados à bandeira do socialismo.

Ainda que considerado por alguns como expectativas irreais de alguns sonhadores, os povos de todo o planeta se irmanam e lutam na perspectiva de que "um outro mundo é possível”. É essa a mensagem que aqui gostaríamos de deixar, investindo-a da noção Freireana do inédito-viável, como "a materialização historicamente possível do sonho almejado. (...) que faz do ato de sonhar coletivamente um movimento transformador" 42 (p. 6).

\section{Colaboradores}

R. H. Simões-Barbosa participou da concepção conceitual, elaboração do projeto e redação final. S. M. Dantas-Berger participou da revisão de literatura, discussão analítica e redação final.

\section{Agradecimentos}

Para o levantamento bibliográfico preliminar desses temas, tivemos a competente ajuda de Nathalya Herzer Reis (à época, aluna de graduação) e Roberto J. G. Unger, bibliotecário do Instituto de Estudos em Saúde Coletiva, Universidade Federal do Rio de Janeiro. A ambos, nossos sinceros agradecimentos. 


\section{Referências}

1. Anyon J. Intersecções de gênero e classe: acomodação e resistência de mulheres e meninas às ideologias de papéis sociais. Cad Pesqui 1990; (73):13-25.

2. Bordo S. O corpo e a reprodução da feminilidade: uma apropriação feminista de Foucault. In: Jaggar AM, Bordo SR, organizadores. Gênero, corpo, conhecimento. Rio de Janeiro: Record/Rosa dos Tempos; 1997. p. 19-41.

3. Simões-Barbosa RH. A 'teoria da práxis': retomando o referencial marxista para o enfrentamento do capitalismo no campo da saúde. Trab Educ Saúde 2010; 8:9-26.

4. Bauman Z. Capitalismo parasitário e outros temas contemporâneos. Rio de Janeiro: Jorge Zahar; 2010.

5. Beck U. Risk society: towards a new modernity. London/Thousand Oaks/New Delhi: Sage; 2005.

6. Departamento de Ações Programáticas Estratégicas, Secretaria de Atenção à Saúde, Ministério da Saúde. Política Nacional de Atenção Integral à Saúde da Mulher: princípios e diretrizes. Brasília: Ministério da Saúde; 2004.

7. Entrevista com Débora Diniz. Direito, saúde e reprodução - como combater o Zika Vírus? http:// www.armadorconceitual.com.br (acessado em 21/ Abr/2016).

8. Giffin KM. A modernidade perversa e a reprodução humana no Brasil. In: Leal MC, Sabroza PC, Rodriguez RH, Buss PM, organizadores. Saúde, ambiente e desenvolvimento. São Paulo: Editora Hucitec/Rio de Janeiro: Abrasco; 1992. p. 99-122.

9. Silver L. Direito à saúde ou medicalização da mulher? Implicações para avaliação dos serviços de saúde para mulheres. In: Giffin K, Costa S, organizadores. Questões da saúde reprodutiva. Rio de Janeiro: Editora Fiocruz; 1999. p. 299-317.

10. Vieira EM. A medicalização do corpo feminino. In: Giffin K, Costa SH, organizadores. Questões da saúde reprodutiva. Rio de Janeiro: Editora Fiocruz; 1999. p. 67-78.

11. Laurell AC. Avançando em direção ao passado: a política social do neoliberalismo. In: Laurell AC, organizadora. Estado e políticas sociais no neoliberalismo. São Paulo: Cortez Editora; 2002. p. 151-78.

12. Rezende MAP. O modelo de gestão do SUS e as ameaças do projeto neoliberal. In: Bravo MIS, Pereira DS, Menezes JSB, Oliveira MMN, organizadores. Política de saúde na atual conjuntura: modelos de gestão e agenda para a saúde. Rio de Janeiro: Rede Sirius/Associação de Docentes da UFRJ-Seção Sindical; 2008. p. 25-35.

13. Carlini EA, Galduróz JCF, Silva AAB, Noto AR, Fonseca AM, Carlini CM, et al. II levantamento domiciliar sobre o uso de drogas psicotrópicas no Brasil: estudo envolvendo as 108 maiores cidades do país: 2005. São Paulo: Centro Brasileiro de Informações sobre Drogas Psicotrópicas/Secretaria Nacional de Políticas Sobre Drogas; 2006.

14. Trotta-Borges MT, Simões-Barbosa RH. As marcas de gênero no fumar feminino: uma aproximação sociológica do tabagismo em mulheres. Ciênc Saúde Coletiva 2009; 14:1129-39.
15. Cesar BAL. O beber feminino: a marca social do gênero feminino no alcoolismo em mulheres [Dissertação de Mestrado]. Rio de Janeiro: Escola Nacional de Saúde Pública, Fundação Oswaldo Cruz; 2005.

16. Nordon DG, Akamine K, Novo NF, Hübner CVK. Características do uso de benzodiazepínicos por mulheres que buscavam tratamento na atenção primária. Rev Psiquiatr Rio Gd Sul 2009; 31:152-8.

17. Carvalho LF, Dimenstein M. O modelo de atenção à saúde e o uso de ansiolíticos entre mulheres. Estud Psicol (Natal) 2004; 9:121-9.

18. Miguelote VRS, Camargo Jr. KR. Indústria do conhecimento: uma poderosa engrenagem. Rev Saúde Pública 2010; 44:190-6.

19. David HMSL, Caufield C. Mudando o foco: um estudo exploratório sobre uso de drogas e violência no trabalho entre mulheres das classes populares da Cidade do Rio de Janeiro, Brasil. Rev Latinoam Enferm 2005; 13(número especial):1148-54.

20. Trotta-Borges MT, Simões-Barbosa RH. Cigarro "companheiro": o tabagismo feminino em uma abordagem crítica de gênero. Cad Saúde Pública 2008; 24:2834-42.

21. Carlini EA, Galduróz JCF, Noto AR, Nappo SA. I levantamento domiciliar sobre o uso de drogas psicotrópicas no Brasil - 2001. São Paulo: Centro Brasileiro de Informações sobre Drogas Psicotrópicas/Secretaria Nacional de Políticas Sobre Drogas; 2002 .

22. Oliveira JF, Paiva MS, Valente CLM. Representações sociais de profissionais de saúde sobre o consumo de drogas: um olhar numa perspectiva de gênero. Ciênc Saúde Coletiva 2006; 11:473-81.

23. Hochgraf PB, Brasiliano S. Mulheres farmacodependentes: uma experiência brasileira. http://apps. einstein.br/alcooledrogas/novosite/atualizacoes/ ac_128.html (acessado em 03/Mar/2011).

24. Berman R. Do dualismo de Aristóteles à dialética materialista: a transformação feminista da ciência e da sociedade. In: Jaggar AM, Bordo SR, organizadores. Gênero, corpo, conhecimento. Rio de Janeiro: Record/Rosa dos Tempos; 1997. p. 241-75.

25. Bosi MLM, Andrade A. Transtornos do comportamento alimentar: um problema de saúde coletiva. Cad Saúde Colet (Rio J.) 2004; 12:197-202.

26. Souto S, Ferro-Bucher JSN. Práticas indiscriminadas de dietas de emagrecimento e o desenvolvimento de transtornos alimentares. Rev Nutr PUCCAMP 2006; 19:693-704.

27. Nappo SA, Carlini EA, Araújo MD, Moreira LFS. Prescription of anorectic and benzodiazepine drugs through notification B prescriptions in $\mathrm{Na}$ tal, Rio Grande do Norte, Brazil. Braz J Pharm Sci 2010; 46:297-303.

28. Secretaria Nacional de Políticas sobre Drogas. I levantamento nacional sobre o uso de álcool, tabaco e outras drogas entre universitários das 27 capitais brasileiras. Brasília: Secretaria Nacional de Políticas sobre Drogas; 2010.

29. Zalaf MRR, Fonseca RMGS. Uso problemático de álcool e outras drogas em moradia estudantil. Rev Esc Enferm USP 2009; 43:132-8. 
30. Giffin KM. Esfera da reprodução em uma visão masculina: considerações sobre a articulação da produção e da reprodução, de classe e de gênero. Physis (Rio J.) 1994; 4:23-40.

31. Giffin KM. Pobreza, desigualdade e equidade em saúde: considerações a partir de uma perspectiva de gênero transversal. Cad Saúde Pública 2002; 18 Suppl:103-12.

32. Brito JC. Enfoque de gênero e relação saúde/trabalho no contexto de reestruturação produtiva e precarização do trabalho. Cad Saúde Pública 2000; 16:195-204.

33. Vargas V. Prólogo. In: Girón A, editor. Género y globalización. Buenos Aires: Consejo Latinoamericano de Ciencias Sociales; 2009. p. 9-12.

34. Hirata H. Globalização e divisão sexual do trabalho. Cadernos Pagu 2001/2002; (17/18);139-56.

35. Bruschini MCA. Trabalho e gênero no Brasil nos últimos dez anos. Cad Pesqui 2007; 37:537-72.

36. Chauí M, Kehl MR, Weber MJ. Educação sexual: instrumento de democratização ou de mais repressão? Temas em debate. Cad Pesqui 1981; (36): 99-110.

\section{Abstract}

The article discusses drug abuse and eating disorders from the critical gender and healthcare perspectives, postulating that subjective suffering can be expressed in the body through psychosomatic illnesses. From this perspective, craving for drugs or superfluous consumer goods, just as illness from self-imposed hunger in pursuit of an ideal of slimness, as in anorexia and bulimia, can be symptoms that expose the woman's suffering. A review in the fields of public health and feminist theories highlights the magnitude of the phenomena of medicalization and commodification of health in the psychiatrization of female discomfort. In the gender transition in capitalist societies, social demands for the performance of old and new women's roles accentuate feelings of inadequacy, expressed as the gender discomfort permeating drug abuse and eating disorders, analyzed as diseases of protest. The study proposes to reclaim the ideals of the Program for Comprehensive Women's Healthcare to deal with such challenges.

Gender and Health; Substance-Related Disorders; Feeding and Eating Disorders; Integrality in Health
37. Freire-Costa J. A fúria de um mundo agonizante. Folha S. Paulo 2003; 1 abr. http://www1.folha.uol. com.br/folha/mundo/ult94u54275.shtml.

38. Kehl MR. O tempo e o cão: a atualidade das depressões. São Paulo: Boitempo; 2009.

39. Xavier D, Ávila MB, Correa S. Questões feministas para a ordem médica: o feminismo e o conceito de saúde integral. In: Labra ME, organizadora. Mulher, saúde e sociedade. Rio de Janeiro: Editora Vozes; 1989. p. 203-22.

40. Secretaria Especial de Políticas para as Mulheres. II plano nacional de políticas para as mulheres. Brasília: Secretaria Especial de Políticas para as Mulheres; 2008.

41. Ministério da Saúde. A política do Ministério da Saúde para atenção integral a usuários de álcool e outras drogas. Brasília: Ministério da Saúde; 2003.

42. Freitas AL. Pedagogia do inédito-viável: contribuições de Paulo Freire para fortalecer o potencial emancipatório das relações ensinar-aprender-pesquisar. In: V Colóquio Internacional Paulo Freire. Recife: Centro Paulo Freire - Estudos e Pesquisas; 2005.

\section{Resumen}

El artículo aborda el abuso de drogas y los trastornos de la alimentación en virtud de las perspectivas críticas de género y la atención de la salud. Se postula que la angustia subjetiva puede ser expresada en el cuerpo a través de las enfermedades psicosomáticas. En esta perspectiva, la insaciable hambre de drogas o bienes superfluos, y la enfermedad por inanición voluntaria en busca de un ideal de delgadez, como en la anorexia y la bulimia, pueden ser sintomas que denuncian sufrimiento femenino. Una revisión en los campos de la salud pública y las teorías feministas destaca la magnitud de los fenómenos de la medicalización y mercantilización de la salud presentes en la psiquiatrización del malestar femenino. En la transición de género de las sociedades capitalistas, cargas sociales para la realización de viejos y nuevos roles femeninos acentuan sentimientos de insuficiencia, traducidos a trastornos de género que rodean el abuso de drogas y de la alimentación, clasificados como enfermedades de protesta. Se propone rescatar los ideales del Programa de Asistencia Integral a la Salud de la Mujer, guiada por la integralidad, para hacer frente a estos desafios.

Género y Salud; Trastornos Relacionados con Sustancias; Trastornos de Alimentación y de la Ingestión de Alimentos; Integralidad en Salud

Recebido em 10/Jul/2016

Versão final reapresentada em 03/Nov/2016

Aprovado em 04/Nov/2016 